\title{
First-line treatment of chronic myeloid leukemia with nilotinib: critical evaluation
}

This article was published in the following Dove Press journal:

Journal of Blood Medicine

28 November 2012

Number of times this article has been viewed

Pier Paolo Piccaluga*

Stefania Paolini*

Clara Bertuzzi

Antonio De Leo

\section{Gianantonio Rosti}

Hematopathology and Hematology

Sections, Department of Hematology and Oncological Sciences, " $L$ and

A Seràgnoli”, S Orsola-Malpighi Hospital, University of Bologna,

Bologna, Italy

*These authors contributed equally to this work
Correspondence: Pier Paolo Piccaluga Molecular Pathology Laboratory, Hematopathology Section, Department of Hematology and Oncology, "L and A Seràgnoli”, S Orsola-Malpighi Hospital, University of Bologna, Via Massarenti,

9-40I 38 Bologna, Italy

Tel +3905 I6364043

Fax +3905 I6364037

Email pierpaolo.piccaluga@unibo.it
Abstract: The therapeutic landscape of chronic myeloid leukemia (CML) has changed dramatically in the last decade. In particular, the availability of imatinib mesylate, a tyrosine kinase inhibitor targeting BCR-ABL, has led to profound and durable remissions in the majority of patients. However, a couple of issues have emerged and partially obscured this scenario. First, it has become clear that a significant proportion of patients either present with primary resistance to imatinib or develop secondary resistance sooner or later during treatment. Second, although the drug is generally well tolerated, a percentage of patients eventually cease treatment because of toxicity. Bearing this in mind, second-generation tyrosine kinase inhibitors have been introduced, including nilotinib. Phase I and II studies indicate remarkable activity for this compound in CML cases resistant to imatinib, including some of those carrying $B C R-A B L 1$ mutants. More recently, two Phase II studies and a III randomized Phase clinical trial demonstrated the superiority of nilotinib compared with imatinib in terms of complete cytogenetic and major molecular responses, which are two relevant surrogate measures of long-term survival in CML. In this paper, we review the most relevant data on nilotinib as first-line treatment for $\mathrm{CML}$, and discuss the rationale for its routine use, as well as some possible future perspectives for CML patients.

Keywords: chronic myeloid leukemia, nilotinib, targeted therapy, $B C R-A B L 1$

\section{Background}

Chronic myeloid leukemia (CML) is a myeloproliferative neoplasm characterized clinically by three distinct phases, ie, chronic, accelerated, and blastic, and occurs in 1.0-1.5 per 100,000 people each year in Western countries. ${ }^{1}$ Of note, CML is the prototype genetic cancer, presenting with the Philadelphia chromosome as a molecular hallmark. This is a truncated derivative of chromosome 22 that arises from the translocation of genetic material between this chromosome and $-\mathrm{t}(9 ; 22)(\mathrm{q} 34 ; \mathrm{q} 11)$ on chromosome 9.2,3 The resulting fusion gene, $B C R-A B L 1$ (breakpoint cluster region, Abelson murine leukemia viral proto-oncogene), encodes for an abnormal, nonmembrane-bound oncoprotein. This oncoprotein is a constitutively active tyrosine kinase that perturbs numerous signal transduction pathways, resulting in uncontrolled cell proliferation, reduced apoptosis, and impaired cell adhesion, and has been shown to induce transformation in vivo, determining CML and acute lymphoblastic leukemia-like syndromes in mice. ${ }^{4,5}$ Two fusion proteins of differing sizes may be produced, ie, p190 and p210, the latter being the one typically found in patients with CML. ${ }^{6}$ The oncoprotein BCR-ABL is associated with deregulated and increased ABL tyrosine kinase activity, ${ }^{7}$ demonstrating activation in multiple signal transduction 
pathways, including Ras/Raf/mitogen-activated protein kinase, phosphatidylinositol 3 kinase, STAT5/Janus kinase, and MYC. ${ }^{8}$ Many of these pathways are used by cytokines to regulate hematopoiesis, thereby allowing $\mathrm{BCR}-\mathrm{ABL}$ to prolong survival and increase proliferation of cells in early leukemogenesis. BCR-ABL has also been shown to associate directly with some of the SRC family tyrosine kinases, including LYN and HCK, which facilitate BCR-ABL coupling to pathways related to transformation. ${ }^{8-11}$

Because BCR-ABL tyrosine kinase activity is necessary for tumor induction and maintenance, this relationship represented an ideal rationale for developing small molecule tyrosine kinase inhibitors. ${ }^{12}$ Remarkably, this led to the approval of the first molecularly targeted drug in 2000, ie, imatinib mesylate $\left(\right.$ Glivec $^{\circledR}$, Novartis Pharma, Basel, Switzerland), which dramatically changed the clinical scenario for CML. ${ }^{13}$ Before introduction of imatinib, effective treatment for CML was limited to a minority of patients. In particular, interferon-alpha (IFN $\alpha$ )-based regimens were shown to improve disease-free and overall survival significantly compared with hydroxyurea, with durable responses induced in $10 \%-30 \%$ of patients. ${ }^{14-16}$ However, this benefit was mostly limited to patients with a low Sokal score and was hampered by significant toxicity. In addition, allogeneic hematopoietic stem cell transplant in the first chronic phase could cure around half of the patients, transplant-related mortality and morbidity were considerable, and many patients were not eligible due to age, comorbidities, or lack of a suitable donor. ${ }^{17,18}$ On the other hand, it was demonstrated in IRIS (International Randomized study of Interferon/IFN versus STI571) that five-year survival in patients diagnosed with CML in the chronic phase improved from approximately $50 \%$ with previous IFN-based regimens to approximately $90 \%$ with imatinib. ${ }^{19,20}$ Of note, IRIS also recognized complete cytogenetic responses and major molecular responses, defined as a 3-log reduction in BCR-ABL transcripts compared with a standardized baseline, as key achievements associated with remarkable long-term outcome, and provided a rationale for using these surrogate endpoints in subsequent clinical trials. ${ }^{18,20-22}$ Of note, this strategy was recently accepted by the European LeukemiaNet and proposed in a consensus guideline ${ }^{21,23}$ (Table 1).

Despite these excellent results, some concerns emerged regarding the actual impact of imatinib therapy. First, it turned out that a substantial fraction of the IRIS patients had left the study, and for a variety of reasons. ${ }^{18,19}$ In fact, at a follow-up of eight years, only $55 \%$ of patients initially treated with imatinib were still receiving the drug, while the
Table I Definition of response to imatinib in chronic phase chronic myeloid leukemia*

\begin{tabular}{|c|c|c|c|}
\hline \multirow{2}{*}{$\begin{array}{l}\text { Evaluation } \\
\text { time }\end{array}$} & \multicolumn{3}{|l|}{ Response } \\
\hline & Optimal & Suboptimal & Failure \\
\hline 3 months & $\begin{array}{l}\mathrm{CHR} \text { and at least } \\
\text { minor } \mathrm{CyR}\end{array}$ & No CyR & No CHR \\
\hline 6 months & $\begin{array}{l}\text { At least } \\
\text { partial CyR }\end{array}$ & $\begin{array}{l}\text { Less than } \\
\text { partial CyR }\end{array}$ & No CyR \\
\hline 12 months & CCyR & Partial CyR & $\begin{array}{l}\text { Less than } \\
\text { partial CyR }\end{array}$ \\
\hline 18 months & MMR & $\begin{array}{l}\text { Less than } \\
\text { partial MMR }\end{array}$ & $\begin{array}{l}\text { Less than } \\
\text { CCyR }\end{array}$ \\
\hline Any time & $\begin{array}{l}\text { Stable or } \\
\text { improving MMR }\end{array}$ & $\begin{array}{l}\text { Loss of MMR, } \\
\text { presence of } \\
\text { mutations }\end{array}$ & $\begin{array}{l}\text { Loss of CHR, } \\
\text { loss of CCyR, } \\
\text { clonal evolution }\end{array}$ \\
\hline
\end{tabular}

Note: *European LeukemiaNet guidelines.

Abbreviations: $\mathrm{CHR}$, complete hematologic response; $\mathrm{CCyR}$, complete cytogenetic response; CyR, cytogenetic response; MMR, major molecular response.

remainder had discontinued therapy, mostly because of an unsatisfactory therapeutic effect or toxicity. ${ }^{18,24}$ Subsequent studies consistently indicated that the clinical outcome with imatinib was significantly less favorable in the community setting. In this regard, a study conducted in the UK showed an event-free survival of only $63 \%$ at 5 years. ${ }^{25}$ In addition, a French group showed that only half of patients had a complete cytogenetic response and were still on treatment at 24 months in a population-based study of CML patients. ${ }^{26}$

Furthermore, resistance to imatinib has emerged as a significant clinical issue. Leukemic cells can develop various mechanisms of resistance during therapy. Specifically, primary resistance is defined as failure to achieve a complete remission despite therapeutic levels of imatinib, whereas secondary or acquired resistance to imatinib arises in the form of a relapse after an initial complete remission has been obtained. Several mechanisms of drug resistance have been postulated, including: expression of a rapid drug efflux protein; extracellular binding of drug molecules; non-BCR-ABL-dependent transforming events; and BCRABL-dependent events involving genetic changes in the ATP binding site that lead to decreased binding affinity for imatinib. Genetic mutations in BCR-ABL result in several possible changes, ie, overexpression of BCR-ABL, disruption of contact points between imatinib and BCR-ABL, and/or structural changes that activate BCR-ABL, thereby preventing the inhibitor from binding. ${ }^{10,27-30}$

Therefore, novel second-generation tyrosine kinase inhibitors, including dasatinib (Sprycel ${ }^{\circledR}$, Bristol-Meyer-Squibb, New York, NY) and nilotinib (formerly AMN107, Tasigna ${ }^{\circledR}$, Novartis Pharma, Basel, $\mathrm{CH}$ ), have been developed and introduced since 2007 . In this paper, we review the available 
data on use of nilotinib as first line-treatment based on our own experience as well as on the literature, and discuss the future perspectives for patients with CML.

\section{Nilotinib as front-line treatment for CML}

Nilotinib is a highly potent BCR-ABL inhibitor that was initially approved for the treatment of patients who have failed prior therapy, including imatinib. Notably, it is active against most imatinib-resistant mutations of BCR-ABL (except T315I) and induces durable cytogenetic responses in approximately $50 \%$ of patients in chronic phase when used as second-line therapy, ${ }^{31,32}$ but responses in patients in advanced phase tend to be transient. Importantly, nilotinib has been recently compared with imatinib in the front-line chronic phase setting.

Initially, the Gruppo Italiano Malattie EMatologiche dell'Adulto (GIMEMA) enrolled 73 patients in a Phase II trial, where patients received nilotinib at a dose of $400 \mathrm{mg}$ twice daily and were followed up for a mean of 30 months. This study confirmed the remarkable efficacy of nilotinib, with complete cytogenetic response, major molecular response, and complete molecular response rates at 24 months of $96 \%, 85 \%$, and $12 \%$, respectively. Only four patients $(5 \%)$ discontinued nilotinib because of toxicity $^{33}$ (Table 2).

Subsequently, a study carried out in the US at the MD Anderson Cancer Center evaluated 51 patients with newly diagnosed CML in chronic phase treated with nilotinib $400 \mathrm{mg}$ twice daily in the front-line setting. ${ }^{34}$ At 24 months, 93\% of patients achieved a complete cytogenetic response and 79\% had a major molecular response (Table 2). Notably, the projected event-free survival was $90 \%$ at 24 months. Treatment was well tolerated, the most frequent grade $3 / 4$ adverse events being neutropenia (12\%) and thrombocytopenia (11\%). Accordingly, at 12 months, the median dose received was $800 \mathrm{mg}$, as initially scheduled. Overall, this study indicated that nilotinib is an effective option for front-line treatment of CML patients in chronic phase. ${ }^{34}$
Finally, the Phase III randomized ENESTnd (Evaluating Nilotinib Efficacy and Safety in Clinical Trials Newly Diagnosed Philadelphia Chromosome Positive) trial compared imatinib $400 \mathrm{mg}$ twice daily with nilotinib $300 \mathrm{mg}$ or $400 \mathrm{mg}$ twice daily as first-line therapy in patients with CML in early chronic phase. ${ }^{35,36}$ At 12 months, major molecular response rates for nilotinib (44\% for the $300 \mathrm{mg}$ dose and $43 \%$ for the $400 \mathrm{mg}$ dose) were significantly superior to that for imatinib $(22 \%, P<0.001) .{ }^{35}$ In addition, on extended follow-up at 24 months, the survival analyses indicated nilotinib $300 \mathrm{mg}$ twice daily as the optimal treatment arm. In particular, compared with imatinib, nilotinib $300 \mathrm{mg}$ twice daily resulted in superior progression-free survival (98\% versus $95.2 \% ; P=0.0437$ ), and improved complete cytogenetic response and major molecular response rates at 24 months $(87 \%$ versus $77 \%, P=0.0018$, and $71 \%$ versus $44 \%, P=0.0001$, respectively). In addition, a significant lower rate of progression to accelerated/blastic phases was recorded in the nilotinib arms. The more frequent side effects were skin rash, myalgia, and increases in bilirubin, lipase and blood glucose on nilotinib, and fatigue, myalgia, and fluid retention on imatinib. ${ }^{35,36}$

Based on these results, nilotinib was approved as frontline therapy for newly diagnosed patients in the US and in some countries in the European Union. Of note, the gap in efficacy in favor of nilotinib has persisted over time, and it appears that nilotinib may improve both short-term (12 months) and long-term ( $\geq 24$ months) outcomes compared with imatinib (Tables 2 and 3 ).

\section{Resistance to nilotinib: beyond second-generation tyrosine kinase inhibitors}

Although nilotinib and other approved second-generation tyrosine kinase inhibitors (eg, dasatinib, which is not discussed in this review), ${ }^{37}$ achieve a significantly improved outcome in the vast majority of patients with CML in chronic phase (CML-CP), a few patients with CML-CP and those with disease in advanced phase still present with primary

Table 2 Response rates with nilotinib as first-line treatment for chronic myeloid leukemia in chronic phase

\begin{tabular}{|c|c|c|c|c|c|}
\hline Clinical phase & Patients (n) & Dose $^{*}$ & CCyR (\%) & MMR (\%) & Reference \\
\hline II & 73 & $400 \mathrm{mg}^{*}$ & $96 *$ & $85 *$ & Rosti et al ${ }^{33}$ \\
\hline ॥ & 51 & $400 \mathrm{mg}^{*}$ & $93 *$ & $79 *$ & Cortes et $\mathrm{a}^{34}$ \\
\hline \multirow[t]{3}{*}{ III } & 846 & $300 \mathrm{mg}(\text { nilotinib })^{*}(\mathrm{n}=282)$ & $80^{\S}(87)^{*}$ & $44^{\S}(7 I)^{*}$ & Saglio et a $a^{35, \S}$ \\
\hline & & $400 \mathrm{mg}(\text { nilotinib) })^{*}(\mathrm{n}=28 \mathrm{I})$ & $78^{\S}(85)^{*}$ & $43^{\S}(67)^{*}$ & Hagop et $\mathrm{al}^{36, *}$ \\
\hline & & $400 \mathrm{mg}$ (imatinib) $(\mathrm{n}=283)$ & $65^{\S}(77)^{*}$ & $22^{\S}(44)^{*}$ & \\
\hline
\end{tabular}

Notes: ${ }^{*}$ Twice daily; $* 24$ months; ${ }^{\circledR} / 2$ months.

Abbreviations: CCyR, complete cytogenetic response; MMR, major molecular response. 
Table 3 Response rates with nilotinib or imatinib in the ENESTnd trial

\begin{tabular}{|c|c|c|c|c|}
\hline & $\begin{array}{l}\text { Nilotinib } 300 \mathrm{mg} \text { BID } \\
\% \text { of patients } \\
(\mathrm{n}=\mathbf{2 8 2})\end{array}$ & $\begin{array}{l}\text { Nilotinib } 400 \mathrm{mg} \text { BID } \\
\% \text { of patients } \\
(\mathrm{n}=\mathbf{2 8 I})\end{array}$ & $\begin{array}{l}\text { Imatinib } 400 \mathrm{mg} \text { QD } \\
\% \text { of patients } \\
(\mathrm{n}=\mathbf{2 8 3})\end{array}$ & $\begin{array}{l}\text { P value } \\
\text { (nilotinib arms } \\
\text { versus imatinib) } \\
\end{array}$ \\
\hline CCyR by 12 months & 80 & 78 & 65 & $<0.00 \mathrm{I}-0.00 \mathrm{I}$ \\
\hline High Sokal risk score & 74 & 63 & 49 & \\
\hline CCyR by 24 months & 87 & 85 & 77 & $0.0018-0.0016$ \\
\hline MMR at 12 months & 44 & 43 & 22 & $<0.000 \mathrm{I}-0.000 \mathrm{I}$ \\
\hline Low Sokal risk score & 41 & 53 & 26 & \\
\hline Intermediate Sokal risk score & 51 & 40 & 23 & \\
\hline High Sokal risk score & 41 & 32 & 17 & \\
\hline MMR at 24 months & 62 & 59 & 37 & $<0.000 \mathrm{I} / 0.000 \mathrm{I}$ \\
\hline CMR (any time) & 26 & 21 & 10 & - \\
\hline Overall survival (\%) & 97.4 & 97.8 & 96.4 & \\
\hline Progression-free survival (\%) & 98 & 97.7 & 95.2 & \\
\hline Discontinued treatment (\%) & 26 & 22 & 33 & - \\
\hline
\end{tabular}

Notes: Adapted from Lancet Oncol, I2, Kantarjian HM, Hochhaus A, Saglio G, et al, Nilotinib versus imatinib for the treatment of patients with newly diagnosed chronic phase, Philadelphia chromosome-positive, chronic myeloid leukaemia: 24-month minimum follow-up of the phase 3 randomised ENESTnd trial, 84I-85I, Copyright 20I I, with permission from Elsevier ${ }^{36}$ and Saglio G, Kim DW, Issaragrisil S, et al. Nilotinib versus imatinib for newly diagnosed chronic myeloid leukemia. N Engl J Med. 20 I0;362:225 I-2259.35

Abbreviations: ENESTnd, Evaluating Nilotinib Efficacy and Safety in Clinical Trials Newly Diagnosed Philadelphia Chromosome Positive; BID, twice daily; QD, once daily; CCyR, complete cytogenetic response; MMR, major molecular response; CMR, complete molecular response.

or secondary resistance. Because $B C R-A B L 1$ mutations are common causes of resistance, much effort have been made to identify compounds able to overcome this phenomenon. In this regard, ponatinib (formerly AP24534), a multitargeted kinase inhibitor, was shown experimentally to be active against all tested BCR-ABL mutants, including T315I, in vitro. ${ }^{38}$ In a Phase I study including mostly patients who had previously failed at least two tyrosine kinase inhibitors, more than $50 \%$ of cases with CML-CP achieved a complete cytogenetic response. ${ }^{39}$ Of interest, the complete response rate was remarkably high (close to $100 \%$ ) in patients carrying the T315I mutation, apparently (and paradoxically) abrogating the prognostically unfavorable effect of this biomarker. ${ }^{18,39}$ Conversely, as expected, the response rate was lower in patients with advanced disease.

On the other hand, emerging evidence supports the concept that tyrosine kinase inhibitor resistance is largely mediated by mechanisms different from tyrosine kinase domain mutations. In fact, many patients with resistance, particularly primary resistance, do not have $B C R-A B L 1$ kinase domain mutations. ${ }^{10,18,40,41}$ In addition, with the exception of the pan-resistant T315I mutant, there is only a partial correlation between in vitro sensitivity and in vivo response, suggesting the contribution of other mechanisms, including ones that are independent of BCR-ABL, ${ }^{42,43}$ as described above. Therefore, treatment of patients with suboptimal response to second-generation tyrosine kinase inhibitors might include agents such as histone deacetylase inhibitors, aurora kinase and Hedgehog pathway inhibitors, omacetaxine, and a combination of tyrosine kinase inhibitors with newer or older compounds, eg, IFN $\alpha .{ }^{44}$ Finally, until novel drugs and combinations emerge as effective strategies in resistant cases, stem cell transplantation should be always considered when a suitable donor is available.

\section{Perspectives}

In light of the aforementioned studies, it is difficult to conclude that every patient with CML should receive frontline treatment with nilotinib or another second-generation tyrosine kinase inhibitor. In favor of this hypothesis is the close association between complete cytogenetic response/ major molecular response and clinical outcome already documented with imatinib, as well as the logic of minimizing the risk of disease progression by reducing the leukemia burden more rapidly and profoundly. ${ }^{18}$ Further, possible differences in the molecular mechanism of the two drugs may support use of nilotinib. In this regard, it was recently shown that imatinib and nilotinib may exert opposite effects on telomere biology and, paradoxically, on cell proliferation. ${ }^{45}$ In particular, inhibition of BCR-ABL by low-dose imatinib has the potential for indirect induction of telomerase activity through regulation of telomeric-associated proteins, namely, overexpression of tankyrase and downregulation of telomeric repeat binding factor 1 interacting nuclear factor $2{ }^{46}$ This leads to lengthening of telomeres and paradoxical enhancement of cell proliferation. Conversely, nilotinib shows inhibitory activity against telomerases, leading to arrest of proliferation. ${ }^{45}$ On the other hand, significant differences in overall survival have yet to be observed with nilotinib (or dasatinib), with longer follow-up being needed. Eventfree survival is excellent in patients with a low Sokal risk score when imatinib is used, suggesting that these patients 
may be managed safely even with a less expensive drug, an issue that will become even more important in the few years after generic imatinib becomes available. ${ }^{18}$ Therefore, it is mandatory to improve our ability to predict outcomes in our patients using ad hoc molecular tests, eg, DNA sequencing and gene expression profiling, in order to offer the optimal strategy to individual patients.

\section{Conclusion}

Recent Phase II and III clinical trials have provided strong evidence for the efficacy and tolerability of nilotinib as first-line treatment for patients with CML, especially those in chronic phase. The faster and more profound therapeutic effects of nilotinib, when compared with imatinib, suggest the possibility of longer event-free and overall survival, as well as a higher number of cured patients. On the other hand, actual long-term efficacy data are still lacking, and pharmacoeconomic concerns have emerged in Western countries in the light of the number of expensive new drugs approved in the last few years and escalating global expenditure by health care systems. Therefore, accurate clinicobiological evaluation, an evidence-based approach, and identification of potential biomarkers are definitely warranted to delineate the best approach in a given case.

\section{Acknowledgments}

The study was financially supported by Bologna AIL, AIRC (5xMille 10007 and IG10519), RFO (Professor Piccaluga), Fondazione Cassa di Risparmio in Bologna, Fondazione della Banca del Monte e Ravenna, Progetto Strategico di Ateneo 2006 (Professor Piccaluga).

\section{Disclosure}

Gianantonio Rosti has been a member of advisory boards for Novartis and Bristol-Myers Squibb (BMS), has acted as a speaker for Novartis, BMS, and Roche, and has received research funding from Novartis. Michele Baccarani has been a member of advisory boards and acted as a consultant and speaker for Novartis and BMS, has been a member of advisory boards for Ariad and Pfizer, and received institutional research funding from Novartis. The other authors report no conflict of interest in this work.

\section{References}

1. Vardiman J, Melo J, Baccarani M, et al. Chronic myelogenous leukaemia, $B C R-A B L 1$ positive. In: Swerdlow S, Campo E, Harris NL, et al, editors. WHO Classification of Tumors of Hematopoietic and Lymphoid Tissue. 4th ed. Lyon, France: International Agency for Research on Cancer; 2008.

2. Baikie AG, Court-Brown WM, Buckton KE, Harnden DG, Jacobs PA, Tough IM. A possible specific chromosome abnormality in human chronic myeloid leukaemia. Nature. 1960;188:1165-1166.
3. Ren R. Mechanisms of BCR-ABL in the pathogenesis of chronic myelogenous leukaemia. Nat Rev Cancer. 2005;5:172-183.

4. Daley GQ, Van Etten RA, Baltimore D. Induction of chronic myelogenous leukemia in mice by the P210bcr/abl gene of the Philadelphia chromosome. Science. 1990;247:824-830.

5. Pear WS, Miller JP, Xu L, et al. Efficient and rapid induction of a chronic myelogenous leukemia-like myeloproliferative disease in mice receiving P210 bcr/abl-transduced bone marrow. Blood. 1998;92: 3780-3792.

6. Kurzrock R, Gutterman JU, Talpaz M. The molecular genetics of Philadelphia chromosome-positive leukemias. NEngl J Med. 1988;319: 990-998.

7. Paul MK, Mukhopadhyay AK. Tyrosine kinase - role and significance in cancer. Int J Med Sci. 2004;1:101-115.

8. Steelman LS, Pohnert SC, Shelton JG, Franklin RA, Bertrand FE, McCubrey JA. JAK/STAT, Raf/MEK/ERK, PI3K/Akt and BCR-ABL in cell cycle progression and leukemogenesis. Leukemia. 2004;18: $189-218$.

9. Van Etten RA. Mechanisms of transformation by the BCR-ABL oncogene: new perspectives in the post-imatinib era. Leuk Res. 2004; 28 Suppl 1:S21-S28.

10. Piccaluga PP, Paolini S, Martinelli G. Tyrosine kinase inhibitors for the treatment of Philadelphia chromosome-positive adult acute lymphoblastic leukemia. Cancer. 2007;110:1178-1186.

11. Piccaluga PP, Rondoni M, Paolini S, Rosti G, Martinelli G, Baccarani M. Imatinib mesylate in the treatment of hematologic malignancies. Expert Opin Biol Ther. 2007;7:1597-1611.

12. Deininger M, Buchdunger E, Druker BJ. The development of imatinib as a therapeutic agent for chronic myeloid leukemia. Blood. 2005;105:2640-2653.

13. O'Brien SG, Guilhot F, Larson RA, et al. Imatinib compared with interferon and low-dose cytarabine for newly diagnosed chronic-phase chronic myeloid leukemia. N Engl J Med. 2003;348: 994-1004.

14. Hehlmann R, Heimpel H, Hossfeld DK, et al. Randomized study of the combination of hydroxyurea and interferon alpha versus hydroxyurea monotherapy during the chronic phase of chronic myelogenous leukemia (CML Study II). The German CML Study Group. Bone Marrow Transplant. 1996;17 Suppl 3:S21-S24.

15. Talpaz M, Kantarjian H, Kurzrock R, Trujillo JM, Gutterman JU. Interferon-alpha produces sustained cytogenetic responses in chronic myelogenous leukemia. Philadelphia chromosome-positive patients. Ann Intern Med. 1991;114:532-538.

16. Hasford J, Baccarani M, Hehlmann R, Anseri H, Tura S, Zuffa E. Interferon-alpha and hydroxyurea in early chronic myeloid leukemia: a comparative analysis of the Italian and German chronic myeloid leukemia trials with interferon-alpha. Blood. 1996;87:5384-5391.

17. Gratwohl A, Hermans J, Goldman JM, et al. Risk assessment for patients with chronic myeloid leukaemia before allogeneic blood or marrow transplantation. Chronic Leukemia Working Party of the European Group for Blood and Marrow Transplantation. Lancet. 1998;352:1087-1092.

18. Eiring AM, Khorashad JS, Morley K, Deininger MW. Advances in the treatment of chronic myeloid leukemia. BMC Med. 2011;9:99.

19. Druker BJ, Guilhot F, O’Brien SG, et al. Five-year follow-up of patients receiving imatinib for chronic myeloid leukemia. $N$ Engl $J$ Med. 2006;355:2408-2417.

20. Hochhaus A, O'Brien SG, Guilhot F, et al. Six-year follow-up of patients receiving imatinib for the first-line treatment of chronic myeloid leukemia. Leukemia. 2009;23:1054-1061.

21. Baccarani M, Cortes J, Pane F, et al. Chronic myeloid leukemia: an update of concepts and management recommendations of European LeukemiaNet. J Clin Oncol. 2009;27:6041-6051.

22. Kantarjian H, O'Brien S, Jabbour E, et al. Impact of treatment end point definitions on perceived differences in long-term outcome with tyrosine kinase inhibitor therapy in chronic myeloid leukemia. J Clin Oncol. 2011;29:3173-3178. 
23. Baccarani M, Saglio G, Goldman J, et al. Evolving concepts in the management of chronic myeloid leukemia: recommendations from an expert panel on behalf of the European LeukemiaNet. Blood. 2006;108:1809-1820.

24. Deininger M, O’Brien SG, Guilhot F, et al. International Randomized Study of Interferon Vs STI571 (IRIS) 8-year follow up: sustained survival and low risk for progression or events in patients with newly diagnosed chronic myeloid leukemia in chronic phase (CML-CP) treated with imatinib. Blood. 2009;114:1126.

25. de Lavallade H, Punnialingam S, Milojkovic D, et al. Pleural effusions in patients with chronic myeloid leukaemia treated with dasatinib may have an immune-mediated pathogenesis. Br J Haematol. 2008; 141:745-747.

26. Lucas CM, Wang L, Austin GM, et al. A population study of imatinib in chronic myeloid leukaemia demonstrates lower efficacy than in clinical trials. Leukemia. 2008;22:1963-1966.

27. Daub H, Specht K, Ullrich A. Strategies to overcome resistance to targeted protein kinase inhibitors. Nat Rev Drug Discov. 2004;3: 1001-1010.

28. Gorre ME, Mohammed M, Ellwood K, et al. Clinical resistance to STI571 cancer therapy caused by BCR-ABL gene mutation or amplification. Science. 2001;293:876-880.

29. Shah NP, Nicoll JM, Nagar B, et al. Multiple BCR-ABL kinase domain mutations confer polyclonal resistance to the tyrosine kinase inhibitor imatinib (STI571) in chronic phase and blast crisis chronic myeloid leukemia. Cancer Cell. 2002;2:117-125.

30. Schindler T, Bornmann W, Pellicena P, et al. Structural mechanism for STI-571 inhibition of abelson tyrosine kinase. Science. 2000;289: 1938-1942.

31. Weisberg E, Manley PW, Breitenstein W, et al. Characterization of AMN107, a selective inhibitor of native and mutant Bcr-Abl. Cancer Cell. 2005;7:129-141.

32. Kantarjian H, Giles F, Wunderle L, et al. Nilotinib in imatinib-resistant CML and Philadelphia chromosome-positive ALL. $N$ Engl J Med. 2006;354:2542-2551.

33. Rosti G, Palandri F, Castagnetti F, et al. Nilotinib for the frontline treatment of $\mathrm{Ph}(+)$ chronic myeloid leukemia. Blood. 2009;114:4933-4938.

34. Cortes JE, Jones D, O'Brien S, et al. Nilotinib as front-line treatment for patients with chronic myeloid leukemia in early chronic phase. J Clin Oncol. 2010;28:392-397.

35. Saglio G, Kim DW, Issaragrisil S, et al. Nilotinib versus imatinib for newly diagnosed chronic myeloid leukemia. N Engl J Med. 2010; 362:2251-2259.
36. Kantarjian HM, Hochhaus A, Saglio G, et al. Nilotinib versus imatinib for the treatment of patients with newly diagnosed chronic phase, Philadelphia chromosome-positive, chronic myeloid leukaemia: 24-month minimum follow-up of the phase 3 randomised ENESTnd trial. Lancet Oncol. 2011;12:841-851.

37. Rosti G, Castagnetti F, Gugliotta G, et al. Second-generation BCR-ABL inhibitors for frontline treatment of chronic myeloid leukemia in chronic phase. Crit Rev Oncol Hematol. 2012;82:159-170.

38. O'Hare T, Shakespeare WC, Zhu X, et al. AP24534, a pan-BCR-ABL inhibitor for chronic myeloid leukemia, potently inhibits the T315I mutant and overcomes mutation-based resistance. Cancer Cell. 2009;16: $401-412$.

39. Cortes J, Talpaz M, Bixby D, et al. A Phase 1 trial of oral ponatinib (AP24534) in patients with refractory chronic myelogenous leukemia (CML) and other hematologic malignancies: emerging safety and clinical response findings. Blood. 2010;116:210.

40. Soverini S, Colarossi S, Gnani A, et al. Contribution of ABL kinase domain mutations to imatinib resistance in different subsets of Philadelphia-positive patients: by the GIMEMA Working Party on Chronic Myeloid Leukemia. Clin Cancer Res. 2006;12:7374-7379.

41. Soverini S, Gnani A, Colarossi S, et al. Philadelphia-positive patients who already harbor imatinib-resistant Bcr-Abl kinase domain mutations have a higher likelihood of developing additional mutations associated with resistance to second- or third-line tyrosine kinase inhibitors. Blood. 2009;114:2168-2171.

42. Hughes T, Saglio G, Branford S, et al. Impact of baseline BCR-ABL mutations on response to nilotinib in patients with chronic myeloid leukemia in chronic phase. J Clin Oncol. 2009;27:4204-4210.

43. Muller MC, Cortes JE, Kim DW, et al. Dasatinib treatment of chronicphase chronic myeloid leukemia: analysis of responses according to preexisting BCR-ABL mutations. Blood. 2009;114:4944-4953.

44. Simonsson B, Gedde-Dahl T, Markevarn B, et al. A randomized Phase II study comparing imatinib and the combination of imatinib and PEGylated interferon alpha-2b in newly diagnosed non-high risk chronic myeloid leukemia (CML) patients in complete hematological remission after imatinib induction therapy. Blood. 2009; 114:3280.

45. Bakalova R, Zhelev Z, Spasov L. Nilotinib versus imatinib: molecular mechanism(s) of its better efficacy. Cancer. April 25, 2012. [Epub ahead of print.]

46. Bakalova R, Ohba H, Zhelev Z, et al. Antisense inhibition of Bcr-Abl/c$\mathrm{Abl}$ synthesis promotes telomerase activity and upregulates tankyrase in human leukemia cells. FEBS Lett. 2004;564:73-84.
Journal of Blood Medicine

\section{Publish your work in this journal}

The Journal of Blood Medicine is an international, peer-reviewed, open access, online journal publishing laboratory, experimental and clinical aspects of all topics pertaining to blood based medicine including but not limited to: Transfusion Medicine; Blood collection, Donor issues, Transmittable diseases, and Blood banking logistics; Immunohematology; Artificial and alternative

\section{Dovepress}

blood based therapeutics; Hematology; Biotechnology/nanotechnology of blood related medicine; Legal aspects of blood medicine; Historical perspectives. The manuscript management system is completely online and includes a very quick and fair peer-review system. Visit http://www.dovepress.com/ testimonials.php to read real quotes from published authors. 